\title{
Needs Assessment for the Global-Mindedness of Vocational Certificate Students under the Office of the Vocational Education Commission
}

Ancharee Chainut

Peerawut Suwanjan

Phadungchai Pupat

Paitoon Pimdee

King Mongkut's Institute of Technology Ladkrabang, Bangkok, Thailand

Doi: 10.2478/mjss-2019-0020

\section{Abstract}

The objectives of the research are as follows: 1) to study the global-mindedness of vocational certificate students; 2) to compare the global-mindedness of these students by grade level, with a sample group of 361 vocational certificate students studying at the vocational certificate level in the 2016 academic year, obtained by stratified random sampling, and 3) to rank the needs for the global-mindedness of these students. The instruments used in the data collection consisted of a questionnaire on the globalmindedness expectation and authenticity of vocational certificate students, which contained 40 questions, covering four aspects, evaluated for content validity by qualified experts. The statistics used in the data analysis were mean, standard deviation, one-way analysis of variance, and the Modified Priority Needs Index (PNI). The research findings are as follows: 1) the level of global-mindedness of the vocational certificate students is high; 2) there were no differences in the global-mindedness of vocational certificate students studying at different grade levels; 3) the needs, ranked in descending order, consisted of acceptance of cultural diversity, attention to global issues, interconnectedness and peace, and world citizenship.

Keywords: global-mindedness; needs assessment; certificate students

\section{Introduction}

Modern advances in communication and information technology are an important factor in the drive for a world without borders, to usher in an age of international economic, social, and political restructuring that requires closer cooperation and mutual reliance. Establishing humanity's good mutual understanding, responsibility, and a sense of unity, with acceptance of and respect for differences and diversity in terms of morals and culture, is a noble ideal to which we must all aspire (National Economic and Social Development Plan Volume 11, 2012-2016). As responsible global citizens (Morjai, Pupat \& Pimdee, 2018). It is essential that each nation learns to adapt and keep up with constant changes and prepares to cope with the aforementioned challenges which human quality. Hence, education is an essential process for the development of quality in people. Quality people naturally stimulate progress in society and the nation (Department of Curriculum and Instruction Development, Ministry of Education, 2002). In order to develop Thailand in the future, it is necessary to consider national development as a member of the global community in addition to making improvements toward resolving existing problems and increasing the quality of life of the 
Thai population. It is unavoidable that development within the trend for globalization will result in borderless development. These changes will certainly influence the need for national development. If human resources are not prepared, through development, to be ready for the aforementioned changes, the nation's population will encounter problems when it tries to adapt and exist in future society (Lawthong. 2001). The national economic and social development plan has set in place proper strategies development plans with urgency in order to provide immunization against risk factors and augmentation in the country's foundation. These cover several aspects, to ensure the strength and development of people and society, to ensure quality and opportunities for accessing resources and benefiting from economic and social development, in an effort to create economic opportunities based on knowledge, and creative thinking based on the foundation of sociallyfriendly production and consumption, in order to lead to secure and sustainable development (National Economic and Social Development Plan Volume 11, 2012-2016). Hence, emphasis must be placed on enhancing available capital to have sufficient strength and energy to achieve drive, especially in people or human capital development, to properly prepare to accommodate changes in the 21st Century.

The development of quality in Thai people and society, based on environmentally-friendly production and consumption, can occur in practice in a structured manner under the principle of achieving development in mission areas, with participation from all sectors in Thai society. This will lead to development for the sustainable benefit and happiness of Thai society under the sufficiency economy philosophy, to achieve a "society that co-exists happily, equally and fairly with immunity against changes" (National Economic and Social Development Plan Volume 11, 2012-2016). An important function of the present study was to develop people by fostering social and cultural values directly and indirectly, explicitly and implicitly (Rakpolamueng. 2006). In doing so, it is necessary to rely on education management as a means of developing people, which forms the basis for national development. Thus, it is necessary to improve Thai youths in every aspect, whether in regards to intellect, knowledge, and skill, or morals and ethics (Department of Curriculum and Instruction Development, Ministry of Education, 2002).

Global-mindedness is a component of the citizens of the world, namely, awareness of world citizenship. Global-mindedness is, therefore, a perception made up of knowledge, thoughts, and key foundations, in addition to behavioral influences. Appropriate research and evaluation provides estimations of modern attitudes towards social consciousness in the processes of modernization and reveal basic moral principles that could become a background of new system of values used in modernizing modern societies. (Buaklay, Pimdee, Pupat, \& Klinhorm, 2018). As a result, needs assessments on global-mindedness is essential to creating citizens of the world who possess awareness about the rights, freedoms, and equality of humanity, and who are without discrimination against different genders, classes, or ethnicities, in order to revolutionize consciousness and achieve awareness; departing from the ego toward consideration of others in order to achieve balance and peace in global society.

(Hett.1993) defined global-mindedness as a view of the world obtained through evaluating the self in relation to global society, and having a sense of responsibility for the world as one of its members. Global-mindedness measures in the context of Thai society and culture (Lawthong. 2001) have been defined as a broad view of the world, with acceptance of different cultures, care for the world's issues, especially in regards to resource utilization and environmental conservation, and the view that every nation has to be interconnected and peaceful, with the consideration that every human in this world is a global citizen imbued with the same rights, freedoms, and equality .

In consideration of the Vocational Certificate Curriculum (VC) of 2013, objectives have been set, as follows: to provide knowledge, skills, and experience, in order to ensure that these are used effectively such that people can choose to engage in professions that are appropriate for themselves, becoming wise and creative people who endeavor to continue learning to develop their quality of life with positive attitudes for the sake of occupation, work, and agency, and who can work effectively as a group while respecting the rights and duties of the self and others, to co-exist responsibly for their families and dedicate themselves to society; to perceive the value of arts and culture; to be conscientious about the sufficiency economy philosophy; to know how to utilize and conserve natural resources and build a good environment; and to become people with good 
character, human relations, morals, and ethics, with self-discipline, awareness, and participation in resolving the economic, social, and political problems of the nation and the rest of the world and with love for the country, the realization of Thainess, and the ability to sacrifice for the whole .

Hence, it is necessary to have global-mindedness, as it requires interactions with humanity, domestically and internationally. Human interactions are a key factor, requiring knowledge and understanding between different populations and nations economically, politically, socially, culturally, traditionally, linguistically, and religiously. It is necessary to view that people in different societies are equal and equivalent to one another, and that all human beings need to face various problems potentially occurring in the future. Hence, development to achieve sustainable benefits and happiness for society requires the creation of a good conscience that can adapt appropriately, suitably, and consistently with the society and culture of each locality, while accepting global changes in the 21st century. In achieving this, students will naturally hold a wide range of perceptions and viewpoints. This is because Thailand has established cultures and traditions that vary depending on the lifestyle of each society, but western culture has affected Thai society in many aspects and has become an important factor in regards to mindsets and morals with respect to human rights and consideration of future consequences to people, society, economy, politics, and environment, in the long-term, from the actions of individuals and groups, from the local to the national and global level, and their potential future positive and negative impacts.

Due to the aforementioned significance, the researcher's interest is in conducting a needs assessment for the global-mindedness of vocational certificate students under the Office of the Vocational Education Commission in order to obtain preliminary data for curriculum development. This could enhance global-mindedness in the students, in order to develop learners and provide them with knowledge, skills, and good attitudes about global-mindedness.

\section{Purposes of the Study}

1. To study the authentic conditions of the global-mindedness of vocational certificate students under the Office of the Vocational Education Commission.

2. To compare these authentic conditions by grade level.

3. To rank the global-mindedness needs of the students.

\section{Conceptual Framework}

The researcher in the present research used the concept of (Lawthong. 2001) in the study by using the following four separate components: acceptance of cultural diversity, attention to global issues, interconnectedness and peace, and global citizenship.

\section{Methodology}

1. Population and Sample

The population used in the research comprised vocational certificate students under the Office of the Vocational Education Commission, of the 2016 academic year, a total of 5,246 subjects (online: Research Statistics of the Office of the Vocational Education Commission, 2016).

The sample group of the research was 361 vocational certificate students at the vocational certificate level, selected by stratified random sampling (Krejcie \& Morgan, 1970).

2. Variables

The independent variables was the grade level (VC 1, 2 and 3).

The dependent variables were as follows:

- the global-mindedness of vocational certificate students, and

- $\quad$ needs for the global-mindedness of the vocational certificate students.

3. Research Instrumentation

The instrument used in the data collection of the research consisted of a five-level scale questionnaire on the global-mindedness of the vocational certificate students, made up of 
40 questions covering four aspects, that was approved for content validity by qualified experts, with instrument reliability of 0.88 for both versions.

4. Data Collection

In the present research, the researcher collected data in the 2016 academic year by sending the questionnaires to the sample group for self-assessment for the globalmindedness of the vocational certificate students, in terms of both expectation and authenticity, using the following assessment criteria:

- A score of 1 meant the student had the lowest level of opinion.

- A score of 2 meant the student had a low level of opinion.

- A score of 3 meant the student had a moderate level of opinion.

- A score of 4 meant the student had a high level of opinion.

- A score of 5 meant the student had the highest level of opinion.

5. Data Analysis

In the present research, the researcher used the following methods in the data analysis:

- The authentic conditions of the global-mindedness of the vocational certificate students were analyzed by using mean and standard deviation with interpretation of mean (Srisaad. 2004) as follows:

$1.00-1.49$ meant the lowest level of opinion.

$1.50-2.49$ meant a low level of opinion.

$2.50-3.49$ meant a moderate level of opinion.

$3.50-4.49$ meant a high level of opinion.

$4.50-5.00$ meant the highest level of opinion.

- A comparison of the authentic conditions of the global-mindedness of the vocational certificate students was analyzed by grade level using one-way ANOVA.

- Ranking of the needs for the global-mindedness of the vocational certificate students were analyzed using the Modified Priority Needs Index (PNI), using the following calculation formula:

$\mathrm{PNI}_{\text {modified }}=\frac{\mathrm{I}-\mathrm{D}}{\mathrm{D}}$

Where:

I means the mean of expectation, and

$D$ means the mean of authenticity.

\section{Empirical Results and Discussion}

\subsection{Demographic data of the questionnaire respondents}

Table 1: Frequency and percentage of questionnaire respondents by grade level

\begin{tabular}{c|c|c}
\hline Grade & Number & $\%$ \\
\hline VC 1 & 175 & 48.48 \\
\hline VC 2 & 102 & 28.25 \\
\hline VC 3 & 84 & 23.27 \\
\hline Total & 361 & 100.00 \\
\hline
\end{tabular}

From Table 1, there were 361 questionnaire respondents in all. When divided by grade, there were 175 Year 1 vocational certificate students (48.48\%), 102 Year 2 vocational certificate students (28.25\%) and 84 Year 3 vocational certificate students $(23.27 \%)$. 


\subsection{Authentic conditions of global-mindedness of vocational certificate students under the Office} of the Vocational Education Commission

Table 2: Means and standard deviations of the authentic conditions of the global-mindedness of vocational certificate students under the office of the vocational education commission $(n=361)$

\begin{tabular}{l|c|c|c|c}
\hline Aspect & Grade & $\bar{X}$ & S.D. & Level \\
\hline \multirow{4}{*}{ Acceptance of cultural diversity } & VC 1 & 4.07 & 0.87 & High \\
\cline { 2 - 5 } & VC 2 & 4.05 & 0.88 & High \\
\cline { 2 - 5 } & VC 3 & 4.09 & 0.87 & High \\
\cline { 2 - 5 } & Total & 4.07 & 0.87 & High \\
\hline \multirow{4}{*}{ Attention to global issues } & VC 1 & 4.22 & 0.84 & High \\
\cline { 2 - 5 } & VC 2 & 4.19 & 0.84 & High \\
\cline { 2 - 5 } & VC 3 & 4.27 & 0.78 & High \\
\cline { 2 - 5 } & Total & 4.23 & 0.82 & High \\
\hline \multirow{4}{*}{ Interconnectedness and peace } & VC 1 & 4.19 & 0.81 & High \\
\cline { 2 - 5 } & VC 2 & 4.25 & 0.75 & High \\
\cline { 2 - 5 } & VC 3 & 4.29 & 0.73 & High \\
\cline { 2 - 5 } & Total & 4.24 & 0.77 & High \\
\hline \multirow{4}{*}{ Oorld citizenship } & VC 1 & 4.23 & 0.83 & High \\
\cline { 2 - 5 } & VC 2 & 4.24 & 0.79 & High \\
\cline { 2 - 5 } & VC 3 & 4.36 & 0.63 & High \\
\cline { 2 - 5 } & Total & 4.27 & 0.75 & High \\
\hline & VC 1 & 4.18 & 0.84 & High \\
\cline { 2 - 5 } & VC 2 & 4.18 & 0.81 & High \\
\cline { 2 - 5 } & VC 3 & 4.25 & 0.75 & High \\
\cline { 2 - 5 } & Total & 4.20 & 0.80 & High \\
\hline
\end{tabular}

From Table 2, the global-mindedness of the vocational certificate students under the Office of the Vocational Education Commission was high overall $(\bar{X}=4.20$, S.D. $=0.80)$, with mean scores ranked in descending order as follows: world citizenship: ( $\bar{X}=4.27$, S.D. $=.075)$, interconnectedness and peace: $(\bar{X}=4.24$, S.D. $=.077)$, attention to global issues: $(\bar{X}=.423$, S.D. $=.082)$, and acceptance of cultural diversity: ( $\bar{X}=.407$, S.D. $=.087$ ). In addition, individual assessment aspects are as follows:

On acceptance of cultural diversity, every item was evaluated with high mean scores, ordered as follows: VC 3 was high $(\bar{X}=4.09$, S.D. $=0.87)$, VC 1 was high $(\bar{X}=4.07$, S.D. $=0.87)$, and VC 2 was high $(\bar{X}=4.05$, S.D. $=0.88)$.

On attention to global issues, every item was evaluated with high mean scores, ordered as follows: VC 3 was high $(\bar{X}=4.27$, S.D. $=0.78)$, VC 1 was high $(\bar{X}=4.22$, S.D. $=0.84)$, and VC 2 was high $(\bar{X}=4.19$, S.D. $=0.84)$.

On interconnectedness and peace, every item was evaluated with high mean scores, ordered as follows: VC 3 was high $(\bar{X}=4.29$, S.D. $=0.73)$, VC 2 was high $(\bar{X}=4.25$, S.D. $=0.75)$, and VC 1 was high $(\bar{X}=4.19$, S.D. $=0.81)$.

On world citizenship, every item was evaluated with high mean scores, ordered as follows: VC 3 was high $(\bar{X}=4.36$, S.D. $=0.63)$, VC 2 was high $(\bar{X}=4.24$, S.D. $=0.79)$, and VC 1 was high $(\bar{X}=4.23$, S.D. $=0.83)$.

Overall, every item was evaluated with high mean scores, ordered as follows: VC 3 was high $(\bar{X}=4.25$, S.D. $=0.75)$, VC 1 was high $(\bar{X}=4.18$, S.D. $=0.84)$, and VC 2 was high $(\bar{X}=4.18$, S.D. $=$ $0.81)$.

The students had had a foundation of learning about the duties of citizens in a previous subject, concerning social responsibility for the self, self-reliance, and respect for the rights of others. This also included no exercising of rights to violate the rights or freedoms of others; respect for differences and acceptance and respect for people who are different, respect for equality by viewing people as equals with a horizontal and not vertical view, respect for the law with 
responsibility to society as a whole, and awareness of the self as a member of society who plays a part in solving problems by not creating problems, and directly taking action toward resolving problems, conscientiously in being a proper citizen. Concurrently, the conceptual framework of (Hett.1993) divides global-mindedness into five components, namely, sense of responsibility, cultural diversity, consequences of actions, world-centered view, and mutual contact and interactions. In addition, research by (Chimthongdi.2007) on education guidelines to promote the global-mindedness of youths found that the overall global-mindedness score of youths was high, with the acceptance of cultural diversity being highest, followed by attention to global issues, interconnectedness and peace, and world citizenship, all of which lead to skills, analytical processes, and positive attitudes about global-mindedness.

\subsection{Comparison of the authentic conditions of the global-mindedness of vocational certificate students under the Office of the Vocational Education Commission by grade}

Table 3: Results of the comparison of the authentic conditions of the global-mindedness of vocational certificate students under the Office of the Vocational Education Commission by grade

\begin{tabular}{|c|c|c|c|c|c|c|}
\hline Aspect & Source of Variation & SS & df & MS & $\mathbf{F}$ & Sig. \\
\hline \multirow{3}{*}{ Acceptance of cultural diversity } & Between Groups & .064 & 2 & .032 & .125 & .883 \\
\hline & Within Groups & 91.636 & 358 & .256 & & \\
\hline & Total & 91.700 & 360 & & & \\
\hline \multirow{4}{*}{ Attention to global issues } & Between Groups & .311 & 2 & .156 & .692 & .502 \\
\hline & Within Groups & 80.563 & 358 & .22 & & \\
\hline & Total & 80.874 & 360 & & & \\
\hline & Between Groups & 576 & 2 & .288 & 1.342 & .263 \\
\hline \multirow[t]{2}{*}{ Interconnectedness and peace } & Within Groups & 76.805 & 358 & .215 & & \\
\hline & Total & 77.381 & 360 & & & \\
\hline \multirow{3}{*}{ World citizenship } & Between Groups & .126 & 2 & .063 & .295 & .742 \\
\hline & Within Groups & 76.772 & 358 & .214 & & \\
\hline & Total & 76.899 & 360 & & & \\
\hline \multirow{3}{*}{ Overall } & Between Groups & 177 & 2 & .088 & .550 & .578 \\
\hline & Within Groups & 57.604 & 358 & 161 & & \\
\hline & Total & 57.781 & 360 & & & \\
\hline
\end{tabular}

From Table 3, the overall mean score of the authenticity of the global-mindedness of vocational certificate students under the Office of the Vocational Education Commission, when divided by grade, was not different in any aspect, with statistical significance at 0.05 . In addition, considering each aspect, there were also no differences in mean scores, with statistical significance at 0.05 . These findings indicate that the students in vocational certificate years 1,2, and 3 have the same authenticity of global-mindedness. This may be due to the fact that the certificate curriculum of 2013 was arranged in such a way that students can learn to gain knowledge, skills, and work experience, with creative thinking and positive attitudes for their professions, with respect to the rights and duties of themselves and others, along with a sense of fairness and ethics and selfdiscipline on every level, with parallel contents. In other words, the learning content is similar on every level, but with increased depth at higher levels. In addition, the students were encouraged to have global-mindedness, possibly because the students were in a good environment and had been well-raised and refined by their families, in addition to being taught and educated in such a way that they had a high level of conscientiousness, sense of responsibility, and global-mindedness with attention to national issues. The aforementioned students have become people with globalmindedness in appreciating and perceiving the values of cultural diversity, and conscientiousness about being a member of society that has to rely on and support others to live together peacefully. This concurs with the research of

(Komondit. 2005) on the global-mindedness of students at King Mongkut's Institute of Technology, Ladkrabang. The study compared the global-mindedness of students at King Mongkut's Institute of Technology, Ladkrabang by year of study, and found no differences in global- 
mindedness, with statistical significance at 0.05. Other studies have found no differences in age and year of study, which concurs with the present study. Examples include studies by Boatler (1992); Deng and Boatler (1993); and Wilson (1975). As for the closed education system at the vocational certificate level under the Office of the Vocational Education Commission, the ages of students in each grade had greater similarity, i.e., age ranged from 15-20 years in each grade, with mixed age groups, because some students completed grade placement examinations prior to enrolling to study at the vocational level. It can be concluded, therefore, that students in different grades do not have different levels of global-mindedness.

\subsection{Ranking of needs for the global-mindedness of vocational certificate students under the Office of the Vocational Education Commission}

Table 4: Analysis of the Modified Priority Needs Index ( $\mathrm{PNI}$ modified)

\begin{tabular}{l|c|c|c|c}
\hline Aspect & Mean Score of authentic (D) & Mean Score of Expectation(I) & PNI $_{\text {modified }}$ & Rank \\
\hline Acceptance of cultural diversity & 4.07 & 5.00 & 0.93 & 1 \\
\hline Attention to global issues & 4.23 & 5.00 & 0.77 & 2 \\
\hline Interconnectedness and peace & 4.24 & 5.00 & 0.76 & 3 \\
\hline World citizenship & 4.27 & 5.00 & 0.73 & 4 \\
\hline
\end{tabular}

From Table 4, the Modified Priority Needs Index had values ranging from $0.73-0.93$. The priority of needs is ranked in descending order as follows: No. 1- Acceptance of cultural diversity: $(D=4.07,1$ $=5.00)$, (PNImodified = 0.93); No. 2- Attention to global issues: $(D=4.23, I=5.00)$, (PNImodified $=$ $0.77)$; No. 3- Interconnectedness and peace: $(D=4.24, I=5.00)$, (PNImodified $=0.76)$, and No. 4World citizenship $(D=4.27, I=5.00)$, (PNImodified $=0.73$ ). This might indicate that students under the Office of the Vocational Education Commission have correct understanding, skills, analytical thinking, and attitudes about global-mindedness, with awareness about life morals and ethics. (Hett. 1993) defined global-mindedness as a worldview based on the evaluation of the self in relation to global society and a sense of responsibility as a member. Concurrently, research by (Lawthong. 2001) on the development of a global-mindedness measurement scale, based on the context of Thai culture and society, defined global-mindedness as a broad worldview with acceptance of cultural diversity and attention to global issues, especially resource utilization and environmental conservation, with the view that every country needs to be interconnected and peaceful and with the consideration that every human being in the world is a citizen of the world and is imbued with the same rights, freedoms, and equality. Global-mindedness based on the context of Thai culture and society is composed of the following: acceptance of cultural diversity as an appreciation and perception of the value of other cultures, without viewing one's own culture as the single best culture, in addition to having interest in learning about foreign cultures and languages and with a desire to interact with foreigners or people from different cultures. This is concurrent with the studies of Barrows.et al.(1981), Cogan and Kubow (1997), Cogan and Derricott (1998), Enloe, Minoura, Willis, and Kitagawa (1991), Hett (1993), and Lentz (1950). Attention to global issues involves caring about and awareness of global issues that exist in the present and will exist in the future, especially in regards to resource utilization and environmental conservation. Concurrent with the research of Barrows.et al. (1981), Cogan and Kubow (1997), and Cogan and Derricott (1998), interconnectedness and peace with the perception of the values of the coexistence of humanity requires mutual reliance, cooperation, and assistance between different nations and the perceived significance of peacefully living together. This is also concurrent with the research of Cogan and Kubow (1997), Cogan and Derricott (1998), and Hett (1993). World citizenship is achieved by perceiving the self as a member of global society, in addition to being a member of individual societies and nations, performing the duties of good citizens, and viewing every human being from every nationality and language as equals who share the same dignity as other equals, in addition to perceiving the values of fellow humans with respect for the rights and freedoms of other humans. This is concurrent with the research of Barrows et al. (1981), Cogan and Kubow (1997), Cogan and Derricott (1998), and Enloe, Minoura, Willis, and Kitagawa (1991). The aforementioned, 
therefore, indicates that every aspect is necessary, and requires the same development. Furthermore, (McKillip. 1987) defined needs as being decisions regarding the value of any given group or person about problems encountered and attempts to obtain solutions, with the following four characteristics: 1 . needs concerning the different values of each person; 2 . needs concerning any specific group; 3 . needs existing in the form of problems arising as a result of insufficient production, and 4 . needs relating to decisions or considerations of solutions to problems.

\section{Conclusion}

This paper 1) studied the global-mindedness of vocational certificate students; 2) compared the global-mindedness of vocational certificate students by grade level, and 3) ranked needs for the global-mindedness of the vocational certificate students. The results were as follows:

The global-mindedness of the vocational certificate students under the Office of the Vocational Education Commission was high overall.

The vocational certificate students in years 1, 2 and 3 had the same authenticity of globalmindedness.

The Modified Priority Needs Index had values ranging from $0.73-0.93$. The priority needs are ranked in descending order as follows: 1) Acceptance of cultural diversity; 2) Attention to global issues; 3) Interconnectedness and peace, and 4) World citizenship.

The obtained results could be applied to develop an enriched curriculum for the globalmindedness of vocational certificate students, allowing them to effectively participate in the global community.

\section{Acknowledgements}

This article was successfully completed with the assistances of Assoc. Prof. Dr. Peerawut Suwanjan, the thesis advisor, Dr. Phadungchai Pupat, and Assoc. Prof. Dr. Paitoon Pimdee the thesis co-advisor, who kindly and consistently provided their advice, support, encouragement, and also help review and make correction all along to finish up the final work. The author wishes to extend sincere appreciation and gratitude for their contributions.

\section{References}

Barrows, T.S.et.al (1981) College student's Knowledge and beliefs : A survey of global understanding. New Rochelle, New York: Chang Magazine Press.

Boatler, R.W. (1992). Worldminded Attitude of International Division Managers Southwest. Journal of Business and Economics 9:22-26.

Buaklay,N., Pimdee, P., Pupat, P., \& Klinhorm, L. (2018). Development of a Curriculum to Enhance the Characteristics of the Future Teaching Professions of Undergraduate Students in Thailand. Mediterranean Journal of Social Sciences, 9(6). Doi: 10.2478/mjss-2018-0177

Chimthongdi, N. (2007). Education guidelines for enhancing global-mindedness among youths, Thesis Dissertation, Chulalongkorn University.

Cogan, J. J. and Kubow, P.K. (1997) Multidimensional citizenship educational policy for the $21^{\text {st }}$ century. Minneapolis: Copyright., page: $23-35$

Cogan, J. J. and Derricott, R. (1998) Citizenship for the $21^{\text {st }}$ Century : an International Perspective on education. London: Kogan page.Department of Curriculum and Instruction Development Ministry of Education. (2002). Academic Journal. Bangkok: Agsornthai Printing

Deng, S. and Boatler, R.W. (1993). Worldmindedness among Canadian Business Students: Implications for Curricula. Journal of Education for Business 68: 94-98.

Enloe, E. Minoura, Y., Willis, D., and Kitagawa, T. (1991). Characteristics of world-minded attitudes of Americans and Japanese, Paper presented at the meeting of the American Educational Research Association: Chicago.

Hett, E. J. (1993). The development of an instrument to measure global-mindedness (Doctoral dissertation). Available from ProQuest Dissertations and Theses database. (UMI No. 9408210)

Kaemket, W. (2008). Research Methods in Behavioral Science. 2nd edition Bangkok: Chulalongkorn University. 
Krejcie, R. V. \& Morgan, D. W. (1970). Determining sample size for research activities. Education and Psychological Measurement. 30(3): 607-610.

Komondit, S. (2005). Global-mindedness of students at the King Mongkut's Institute of Technology Ladkrabang. Bangkok: Master of Education Thesis Dissertation, Vocational Education Teaching and Curriculum, King Mongkut's Institute of Technology Ladkrabang.

Lawthong, N. (2001). The Development of Global-Mindedness Measure in the context of Thai culture and society. Bangkok: Doctoral Thesis in education, Educational Research, Chulalongkorn University.

Lentz, T.F. (1950). The Attitudes of World Citizenship. The Journal of Social Psychology 32: 207-214.

McKillip, J. (1987). Need analysis: Tools for the human services and education. Newbury Park, Calif: Sage Publications.

Morjai, W., Pupat, P., \& Pimdee, P. (2018). Development of Indicators on Automotive Technology Skills of Vocational Diploma Students: A Confirmatory Factor Analysis Model. Mediterranean Journal of Social Sciences, 9(5). Doi : 10.2478/mjss-2018-0152

Rakpolamueng, C. (2006). Duty and Role. Bangkok: 1 edition.Research Statistics of the Office of the Vocational Education Commission Available (2016) at http://www.techno.vec.go.th/Default.aspx?tabid=659 Office of the Vocational Education Commission.

Srisaad, B. (2004). Preliminary research. 7th edition Bangkok: Suviriyasarn.

The Eleventh National Economic and Social Development Plan. B.E. 2555 - 2559, (2012 - 2016) from: http://www.nesdb.go.th Office of the National Economic and Social Development Board, The Prime Minister's Office.2012 Vocational Certificate Curriculum, (2013). Online Available at: http://www.thatum.ac.th/rthatum/lk.pdf

Wilson, L. (1975). The attitude of elementary teachers toward nationalism and worldmindedness. Unpublished Doctoral Dissertation; Drake University, Des Moines.

Wongwanich, S. (2015). Needs Assessment. $3^{\text {rd }}$ ed. Bangkok: Chulalongkorn University. 